\title{
Serum Lipopolysaccharide-Binding Protein Concentrations in Trauma Victims
}

\author{
STEVEN C. CUNNINGHAM, ${ }^{1 *}$ DEBRA L. MALONE, ${ }^{1}$ GRANT V. BOCHICCHIO, ${ }^{1}$ \\ THOMAS GENUIT, ${ }^{1}$ KASPAR KELEDJIAN, ${ }^{1}$ J. KATHLEEN TRACY, ${ }^{2}$ \\ and LENA M. NAPOLITANO 3
}

\begin{abstract}
Background: In low concentrations, lipopolysaccharide-binding protein (LBP), an acute-phase protein recognizing lipopolysaccharide (LPS), catalyzes its transfer to the cellular receptor consisting of CD14 and Toll-like receptor-4. Previous studies have documented increased serum LBP concentrations in patients with sepsis, systemic inflammatory response syndrome (SIRS), or acute pancreatitis and after cardiopulmonary bypass. No prior studies have examined LBP expression in trauma victims. We hypothesized that admission LBP plasma concentrations are predictive of outcome (mortality) in trauma. This study assessed time-dependent changes in serum LBP concentrations in trauma patients soon after injury.

Methods: A prospective, single-institution, observational cohort study of $\mathbf{1 2 1}$ adult trauma patients (age $\geq 17$ years) with moderate to severe injury who required hospitalization. The trauma patients were male in $79.6 \%$ of the cases and had a mean age of $43.0 \pm 20.6$ years. The mean injury severity score (ISS) was $23 \pm 12$, and the crystalloid resuscitation volume given in the first $24 \mathrm{~h}$ averaged 6,640 $\pm 3,729 \mathrm{~mL}$. Informed consent was obtained on admission, and blood samples were drawn on admission and at $24 \mathrm{~h}$ postadmission. Prospective data were collected for daily SIRS score, multiple organ dysfunction score (MODS), and sequential organ failure assessment (SOFA) score, complications, and outcomes. Plasma concentrations of LBP were measured by enzyme-linked immunosorbent assay.

Results: Sixty patients $(48.8 \%$ of the study cohort) required emergency surgical intervention and sustained a substantial intraoperative blood loss (mean 1,404 $\pm 2,757 \mathrm{~mL}$ ). The hospital mortality rate was $16.3 \%$ (20 patients). The mean intensive care unit stay was $8.9 \pm 16.4$ days, and the hospital stay was $14.8 \pm 19.6$ days. The patients had a significantly higher serum concentrations of LBP on admission (mean $28.0 \pm 25.3 \mathrm{mg} / \mathrm{L}$; range $2-100 \mathrm{mg} / \mathrm{L}$ ) than did control subjects (mean $6.2 \pm 2.1 \mathrm{mg} / \mathrm{L}$; range $1.3-12.8 \mathrm{mg} / \mathrm{L} ; \mathrm{p}<0.01$ ), similar to the plasma concentrations previously reported in septic patients. A significant increase in LBP concentration was noted at $24 \mathrm{~h}$ (mean $72.3 \pm 45.7 \mathrm{mg} / \mathrm{L}$; range $8-210 \mathrm{mg} / \mathrm{L} ; \mathrm{p}<0.05)$. The admission LBP concentration was significantly greater in nonsurvivors than in survivors. However, after controlling for age and ISS, the admission LBP concentration did not predict death.
\end{abstract}

Departments of ${ }^{1}$ Surgery and ${ }^{2}$ Epidemiology, University of Maryland School of Medicine, Baltimore, Maryland.

${ }^{3}$ Department of Surgery, University of Michigan School of Medicine, Ann Arbor, Michigan.

Presented at the Surgical Infection Society 24 ${ }^{\text {th }}$ Annual Meeting, Indianapolis, IN, April 29-May 1, 2004.

*Recipient of 2004 Surgical Infection Society Resident Award.

Supported by a grant from the Office of Naval Research. 
Conclusions: In this prospective study of trauma patients, LBP concentrations were significantly increased early post-injury (on admission), and higher concentrations were associated with a higher mortality rate. However, the independent prognostic value of admission LBP was not incremental to clinical outcome predictors (age and ISS) in logistic regression analysis. Additional studies are necessary to determine the peak and nadir LBP concentrations. The serum concentration of LBP in trauma victims soon after injury may have prognostic importance, and further studies are warranted.

\section{INTRODUCTION}

$\mathbf{T}$ RAUMA ACCOUNTS for hospital admission of 1.8 million persons annually in the United States [1]. Infection is a major cause of morbidity in the trauma patient population, with $40 \%$ to $50 \%$ of severely injured patients developing serious infections $[2,3]$. Systemic inflammatory response syndrome (SIRS) and multiple organ dysfunction are important clinical complications of trauma for which no satisfactory therapy is available [4]. Multiple organ dysfunction remains the most common cause of late death in critically ill trauma patients.

Biologic mediators play a key role in the development of SIRS and multiple organ dysfunction. The release of mediators depends primarily on the severity of tissue trauma and shock and secondarily on the activation of various cascades that culminate in the expression of polymorphonuclear neutrophil-derived substances, cytokines, and adhesion molecules. Similarly, a number of specific biomarkers-a measure that identifies a biologic state or that predicts the presence or severity of a pathologic process or disease-have been identified in sepsis and are prognostic markers for patients at higher risk of death [5]. Delineation of timedependent alterations in specific mediators after trauma, and determination of accurate predictors of SIRS and multiple organ dysfunction, will provide critical information for the development of appropriate therapeutic modalities for this disease and its complications.

Lipopolysaccharide-binding protein (LBP) is an acute-phase protein that catalyzes the transfer of lipopolysaccharide (LPS) to a cellular receptor $[6,7]$ consisting of CD14 and a member of the Toll-like receptor family. In low concentrations, LBP enhances the cell's response to tumor necrosis factor (TNF) [8,9], but in high concentrations, LBP inhibits LPS effects and protects mice from an otherwise-lethal infection [10]. A single LBP molecule may transport hundreds of LPS molecules to CD14 [11] but also transports LPS to other acceptors, including high-density lipoprotein [12-14], which neutralizes the potency of LPS. These data document a dual role for LBP in both enabling and inhibiting host responses to LPS.

Lipopolysaccharide-binding protein also has been recognized as a marker of overall inflammation in SIRS. Previous studies have documented higher serum LBP concentrations in patients with sepsis [15], SIRS [16], or acute pancreatitis [17] and after cardiopulmonary bypass [18]. Because LBP initially was appreciated as an acute-phase response protein whose expression was triggered by infection-first gram-negative [19] and later gram-positive, fungal, and mycobacterial [20-22] infectionsseveral recent studies have investigated the ability of the serum LBP concentration to distinguish between infective and non-infective causes of early SIRS, with various results in different populations. In a study of neutropenic cancer patients, the LBP concentration at the onset of febrile neutropenia was significantly higher in patients with gram-negative bacteremia that in those with fever of unknown origin [23]. In contrast, Prucha et al. concluded that LBP is a nonspecific marker of the acutephase response in non-neutropenic adults and cannot be used to differentiate infective from non-infective SIRS [24].

Several studies have evaluated the effect on LBP of burns in animals $[25,26]$, but to our knowledge, no studies have examined LBP expression in human victims of trauma. We hypothesized that the admission LBP plasma concentration is predictive of outcome (mortality) in trauma. This study assessed time-dependent changes in serum LBP concentrations in trauma patients soon after injury. 


\section{PATIENTS AND METHODS}

\section{Setting and study design}

This prospective observational cohort study was conducted at the R. Adams Cowley Shock Trauma Center of the University of Maryland, the statewide adult trauma center. Over a 12month period (October 1999 to October 2000), 121 trauma patients with moderate to severe injury were enrolled at the time of hospital admission. Written informed consent was obtained from all patients or surrogates. The inclusion criteria were age $\geq 17$ years, major intra-abdominal injury, pelvic fracture, fracture of two or more long bones, hypovolemia, shock, or any admission to the intensive care unit (ICU). Exclusion criteria were transfers, death within 24 hours, pregnancy, known acquired immunodeficiency syndrome, chemotherapy, and transplanted organ or other chronic immune disorders. Blood samples were drawn at admission and $24 \mathrm{~h}$ after admission. Prospective data were collected for daily SIRS [27], multiple organ dysfunction score (MODS), and sequential organ failure assessment (SOFA) score [28], complications, outcome, and injury severity score (ISS) [29]. This study was approved by the Human Institutional Review Board of the Office of Research Subjects of the University of Maryland School of Medicine.

\section{LBP assay}

Blood was collected in sterile endotoxin-free tubes containing ethylenediaminotetraacetic acid or citrate and cooled to $4^{\circ} \mathrm{C}$. After centrifugation, the plasma was removed and immediately frozen at $-80^{\circ} \mathrm{C}$. The LBP concentration in the plasma samples was measured in duplicate using the Human LBP solid-phase enzyme-linked immunosorbent assay (Cell Sciences, Norwood, MA). The functional limit of detection of this assay is $1 \mathrm{ng} / \mathrm{mL}$. This assay has a large measurable concentration range, from 1-100 ng/mL, with high sensitivity, specificity, and reproducibility. All patients had LBP measured on admission, and 96 patients had repeat measurement at $24 \mathrm{~h}$. Twenty healthy adults were used as control subjects (mean age 35 years; $80 \%$ male).

\section{Statistics}

The mean values and standard deviations were calculated for each parameter. Categorical variables were compared using Pearson chisquare and contingency table analysis. Significance was accepted where $p$ was $<0.05$. Analysis of variance (ANOVA) and multiple logistic regression analysis were used for binary outcomes, including two main covariates (age and ISS). Continuous variables were compared using ANOVA and multiple linear regression analysis. Statistical analyses were performed using the Stata 7.0 Special Edition software package (Stata Corporation, College Station, TX).

\section{RESULTS}

\section{Clinical characteristics}

The characteristics of the study population are presented in Table 1 . The patients were predominantly male $(79.3 \%)$, and $35 \%$ were of non-Caucasian race. All had sustained moderate to severe injuries with a mean ISS of 23. Emergency surgery was required by $48 \%$ of the

Table 1. Clinical Characteristics of 121 Patients IN STUDy COHORT

\begin{tabular}{lcc}
\hline Mean age (years) (SD) & 43.0 & $(20.7)$ \\
Male (\%) & 96 & $(79.3)$ \\
Non-Caucasian race (\%) & 42 & $(34.7)$ \\
Mean Injury Severity Score (SD) & 23 & $(12)$ \\
Glasgow Coma Score on & 11 & $(5)$ \\
$\quad$ admission (SD) & 132 & $(32)$ \\
Systolic blood pressure on & & \\
$\quad$ admission (mm Hg)(SD) & 60 & $(48.8)$ \\
Emergency operation (n, \%) & 1,407 & $(2,757)$ \\
Intraoperative blood loss (mL)(SD) & & $(3,729)$ \\
Crystalloid resuscitation in first & 6,640 & \\
$\quad$ 24 h (mL)(SD) & 72 & $(64.3)$ \\
ICU admission (n, \%) & 15.2 & $(19.2)$ \\
ICU length of stay (days)(SD) & 13.8 & $(17.5)$ \\
Hospital length of stay (days)(SD) & 22 & $(18.2)$ \\
Hospital mortality (n, \%) & 2.55 & $(1.02)$ \\
SIRS score on admission (SD) & 3.50 & $(3.01)$ \\
SOFA score on admission (SD) & 87 & $(71.9)$ \\
Multiple organ dysfunction on & & \\
$\quad$ admission (n, \%) & 3.9 & $(3.4)$ \\
MODS on admission (SD) & & \\
\hline
\end{tabular}

Abbreviations: SIRS = systemic inflammatory response score; SOFA = sequential organ failure assessment; MODS = multiple organ dysfunction score. 
Table 2. Patient Characteristics by Multiple Organ DYSFUNCTION SCORE (MODS)

\begin{tabular}{|c|c|c|c|}
\hline & MODS & $=0$ & $M O D S>0$ \\
\hline $\mathrm{N}(\%)$ & 22 & $(20.2)$ & $87 \quad(79.8)$ \\
\hline Mean age (years)(SD) & 42.1 & (19.3) & 43.2 (21.4) \\
\hline Non-Caucasian race $(n, \%)$ & 8 & $(22.2)$ & $28 \quad(77.8)$ \\
\hline Injury Severity Score (SD) & 17 & (9) & $25 \quad(12)^{a}$ \\
\hline $\begin{array}{l}\text { Systolic blood pressure on } \\
\text { admission }(\mathrm{mm} \mathrm{Hg})(\mathrm{SD})\end{array}$ & 145.8 & $(23.4)$ & $128.6(33.6)^{a}$ \\
\hline ICU admission (n, \%) & 8 & $(38.1)$ & $57 \quad(69.5)^{\mathrm{a}}$ \\
\hline $\begin{array}{l}\text { ICU length of stay (days) } \\
\text { (SD) }\end{array}$ & 5.17 & $(2.8)$ & $15.84(19.9)$ \\
\hline $\begin{array}{l}\text { Hospital length of stay } \\
\text { (days)(SD) }\end{array}$ & 7.43 & $(6.9)$ & $14.67(18.9)^{b}$ \\
\hline $\begin{array}{l}\text { MODS score on } \\
\text { admission (SD) }\end{array}$ & & 0 & $4.84(3.1)^{\mathrm{a}}$ \\
\hline Mortality (n, \%) & & 0 & $(16.5)$ \\
\hline $\begin{array}{l}\text { Admission LBP (mg/L) } \\
\text { (SD) }\end{array}$ & 30.4 & $(24.0)$ & $27.3 \quad(26.9)$ \\
\hline 24-hour LBP (mg/L)(SD) & 69.5 & $(44.3)$ & $72.2 \quad(45.1)$ \\
\hline
\end{tabular}

ap $<0.05$

bP $<0.10$.

Abbreviation: LBP $=$ lipopolysaccharide-binding protein; $\mathrm{LOS}=$ length of stay.

patients with a mean intraoperative blood loss of 1,407 $\pm 2,757 \mathrm{~mL}$ and a mean 24 -h crystalloid fluid resuscitation volume of $6,640 \mathrm{~mL}$. Admission to the ICU was required by $64 \%$ of the patients with a mean length of stay (LOS) of 15 days. The mean hospital LOS was 14 days. The hospital mortality rate was $18 \%$. No significant differences in clinical characteristics were observed between the patients who had complete LBP data available and those who did not.
The majority of the study population had evidence of SIRS and organ dysfunction on admission, as measured by the SOFA and MODS. Patients with multiple organ dysfunction on admission had a significantly higher ISS, lower systolic blood pressure, and higher ICU admission rate. Patients with multiple organ dysfunction also tended to have a longer ICU LOS and to be of non-Caucasian race; however, the differences were not statistically significant (Table 2).

\section{LBP concentrations at admission and at $24 \mathrm{~h}$}

The patients had significantly higher LBP plasma concentrations on admission (mean $28.0 \pm 25.3 \mathrm{mg} / \mathrm{L}$; range $2-100 \mathrm{mg} / \mathrm{L}$ ) than did the control subjects (mean $6.2 \pm 2.1 \mathrm{mg} / \mathrm{L}$; range $1.3-12.8 \mathrm{mg} / \mathrm{L} ; \mathrm{p}<0.01$; Fig. 1 ). The plasma LBP concentrations at $24 \mathrm{~h}$ were significantly higher than the admission values (mean $72.3 \pm 45.7 \mathrm{mg} / \mathrm{L}$; range $8-210 \mathrm{mg} / \mathrm{L}$; $\mathrm{p}<0.05$; Fig. 1). Figure 2 shows the distribution of the plasma LBP concentrations on admission and $24 \mathrm{~h}$ after injury. All LBP data displayed are for the 96 patients who had measurements both at admission and at $24 \mathrm{~h}$.

Patients were categorized into either a lowLBP group ( $<20 \mathrm{mg} / \mathrm{L}$ on admission) or a highLBP group ( $\geq 20 \mathrm{mg} / \mathrm{L}$ on admission) on the basis of the observation that a serum LBP concentration of $20 \mathrm{mg} / \mathrm{L}$ is two standard deviations above the mean for normal subjects [16].

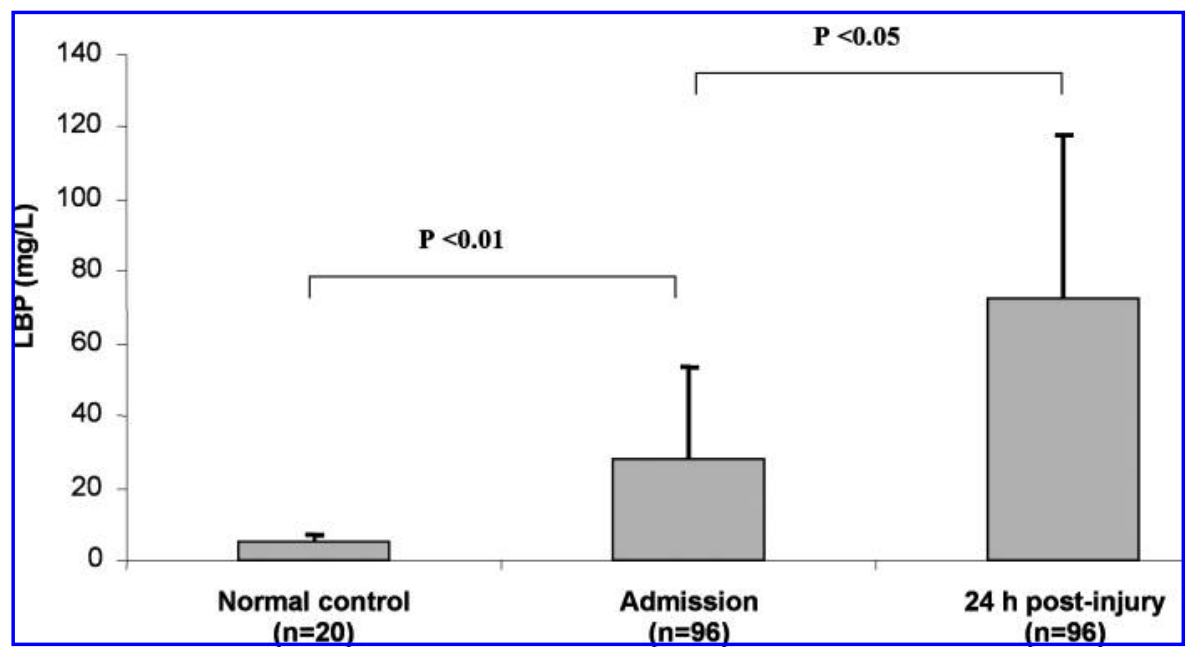

FIG. 1. Lipopolysaccharide-binding protein concentration in control subjects and in trauma patients on admission and 24 h post-injury. Values are mean \pm standard deviation. 


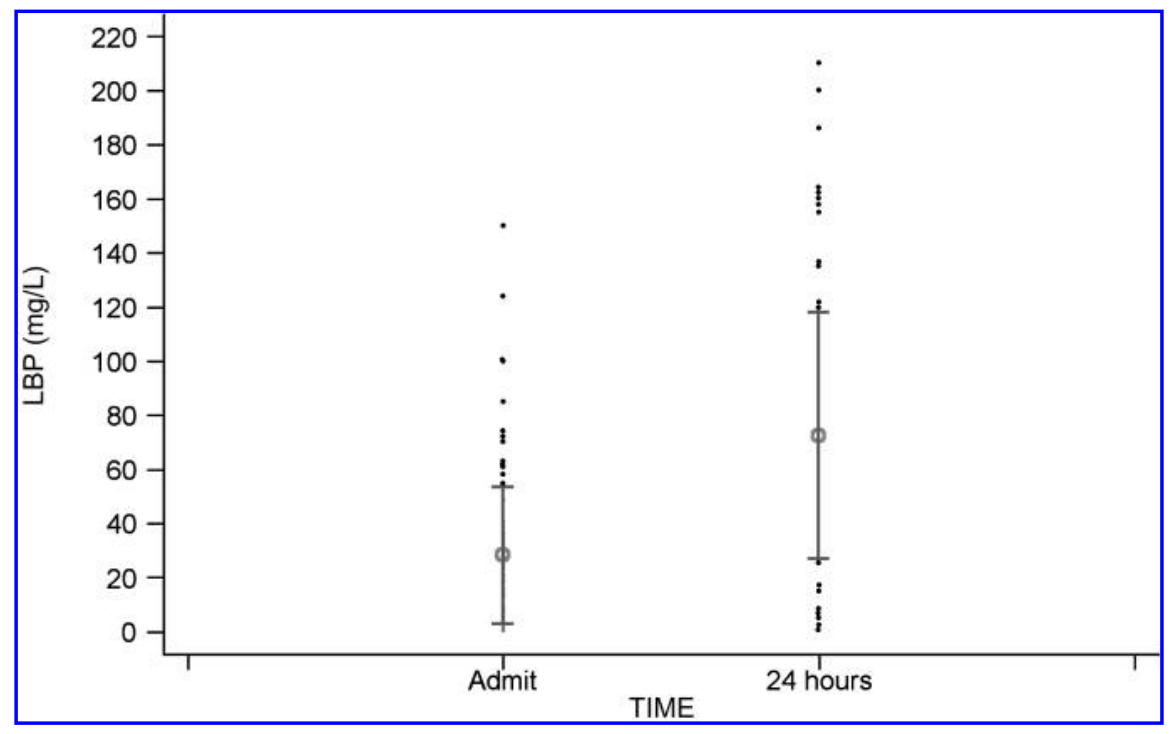

FIG. 2. Lipopolysaccharide-binding protein (LBP) distribution at trauma admission and $24 \mathrm{~h}(\mathrm{n}=96)$. Bars represent mean \pm 1 SD.

The mean LBP concentration in the low-LBP group $(\mathrm{n}=44)$ was $11.04 \pm 5.48 \mathrm{mg} / \mathrm{L}$ vs. $42.66 \pm 26.56 \mathrm{mg} / \mathrm{L}$ in the high-LBP group $(\mathrm{n}=52 ; \mathrm{p}<0.05)$. Interestingly, by $24 \mathrm{~h}$, the LBP concentrations in patients in the low-LBP group had increased to approximately the same mean value as in patients in the high-LBP group $(65.43 \pm 47.34 \mathrm{mg} / \mathrm{L}$ vs. $78.17 \pm 43.80$ $\mathrm{mg} / \mathrm{L})$.
Correlation of LBP with age, sex, and ISS

The characteristics of the high-LBP and lowLBP groups are shown in Table 3. Patients in the high-LBP group were significantly older (mean age 38.1 vs. 46.8 years). When stratified by age (Fig. 3) patients older than 65 years had significantly greater plasma LBP concentrations than patients younger than 46 years

Table 3. Patient Characteristics by Lipopolysaccharide-Binding Protein CONCENTRATION ON AdMission

\begin{tabular}{lccccc}
\hline & $L B P \leq 20 m g / L$ & \multicolumn{2}{c}{$L B P>20 m g / L$} \\
\hline N (\%) & 44 & & 52 & \\
Mean age (years)(SD) & 38.1 & $(18.0)$ & 46.8 & $(21.5)^{\mathrm{a}}$ \\
Non-Caucasian race (n, \%) & 14 & $(31.8)$ & 18 & $(34.6)$ \\
Injury Severity Score & 24 & $(12)$ & 20 & $(10)$ \\
Glasgow Coma Score on admission (SD) & 11 & $(5)$ & 12 & $(4)$ \\
Systolic blood pressure on admission & 128.7 & $(36.1)$ & 138.0 & $(27.7)$ \\
$\quad$ (mm Hg)(SD) & 28 & $(66.7)$ & 30 & $(65.2)$ \\
ICU admission (n, \%) & 15.0 & $(17.9)$ & 10.4 & $(11.8)$ \\
ICU length of stay (days)(SD) & 15.1 & $(19.2)$ & 12.2 & $(11.6)$ \\
Hospital length of stay (SD) & 3 & $(6.8)$ & 7 & $(13.5)$ \\
Mortality (n, \%) & 2.5 & $(0.9)$ & 2.7 & $(1.0)$ \\
SIRS score on admission (SD) & 4.00 & $(3.7)$ & 2.95 & $(2.9)$ \\
MODS score on admission (SD) & 3.66 & $(3.2)$ & 2.68 & $(2.6)$ \\
SOFA score on admission (SD) & & & & \\
\hline
\end{tabular}

ap $<0.05$.

Abbreviations: SIRS = systemic inflammatory response syndrome score; MODS = multiple organ dysfunction syndrome score; SOFA = sequential organ failure assessment. 


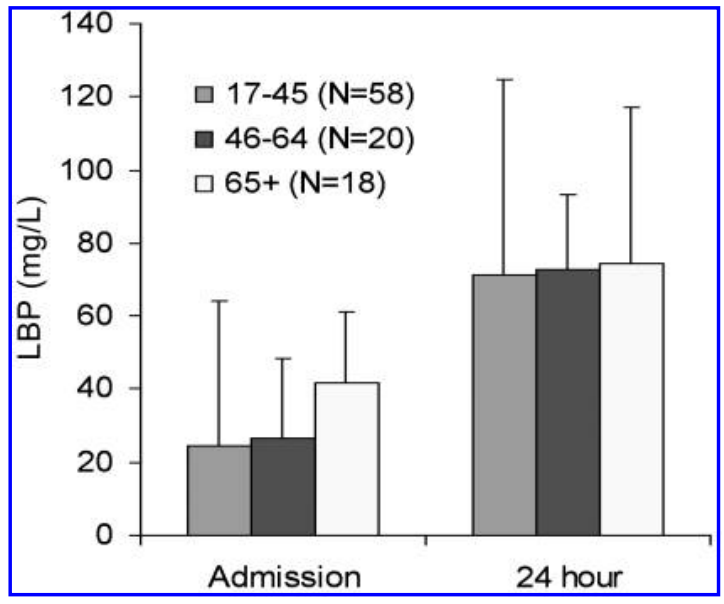

FIG. 3. Lipopolysaccharide binding protein (LBP) concentrations at admission and $24 \mathrm{~h}$ by age group (mean \pm SD; $n=96$ ). Greater age (age $>65$ years) was associated with higher LBP concentration on admission $(p=0.023)$.

$(41.7 \pm 39.6 \mathrm{mg} / \mathrm{L}$ vs. $26.56 \pm 21.57 \mathrm{mg} / \mathrm{L} ; \mathrm{p}=$ 0.023).

Male and female patients had similar concentrations of LBP on admission and at $24 \mathrm{~h}$ (Fig. 4). Likewise, no differences in plasma LBP concentrations were identified on the basis of injury severity. The mean ISS score was not significantly different in the high-LBP vs. the lowLBP group (Table 3).

\section{Correlation of LBP with outcome}

Having established that plasma LBP concentrations were significantly higher in trauma patients on admission and at $24 \mathrm{~h}$ after injury, we sought to correlate LBP with outcome. The admission LBP concentration was significantly greater in patients who did not survive than in survivors by $t$-test ( $\mathrm{p}=0.0244$; Fig. 5). Using a cutoff of $>20 \mathrm{mg} / \mathrm{L}$ (which represented the best discrimination, as derived from receiver operator characteristic curves), LBP as a predictor of death had a sensitivity $86.4 \%$ and a specificity of $59.5 \%$. Logistic regression analysis confirmed that nonsurvivors had significantly higher plasma LBP concentrations on admission. There was a 1.02-fold increase in the odds of death for every unit increase in LBP at admission $(\mathrm{p}=0.042$; Table 4$)$.

Further analysis of admission LBP (high vs. low) by logistic regression revealed that the high-LBP group had a $>2$-fold higher risk of death than the low-LBP group. However, given the small sample size, this difference did not reach statistical significance $(p=0.297$; Table $4)$. Because age and ISS were confirmed previously as independent predictors of outcome in trauma, we performed a multiple logistic regression analysis with age and ISS as covariates. In this analysis, the LBP group was no longer an independent predictor of death.

\section{Correlation of LBP with SIRS} and organ dysfunction

No correlation of plasma LBP concentration (admission or $24 \mathrm{~h}$ ) with the presence of SIRS or organ failure (as measured by admission and daily SOFA score and MODS) was identified. The time courses of serial daily scores are depicted in Figure 6 for patients in the high-LBP vs. low-LBP group; no significant differences were identified.

\section{DISCUSSION}

Lipopolysaccharide-binding protein is an acute-phase protein that enhances the responsiveness of immune cells to LPS by virtue of its capacity to transfer it to CD14. The protein plays an integral part in the LPS-mediated release of inflammatory cytokines. Both LBP and the LPS receptor CD14 represent key molecules in the pathophysiologic alterations induced by

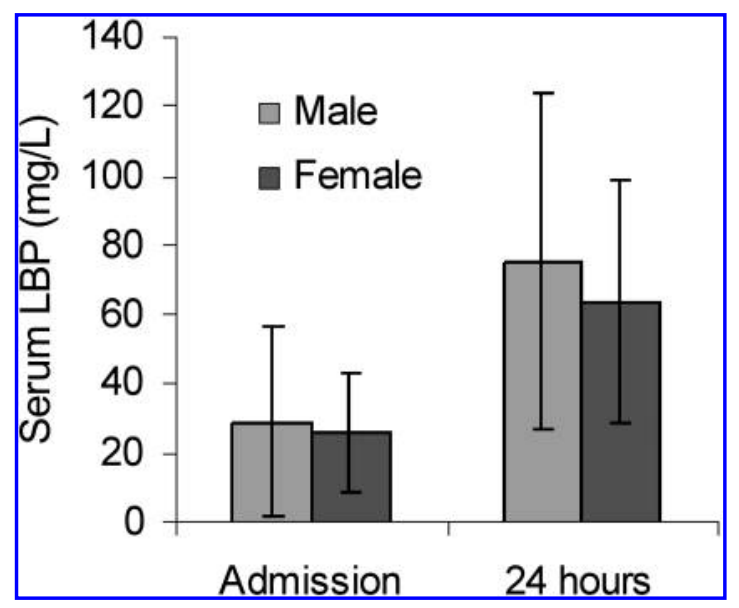

FIG. 4. Concentration of lipopolysaccharide-binding protein in trauma patients by sex $(n=96)$. No difference was identified. 


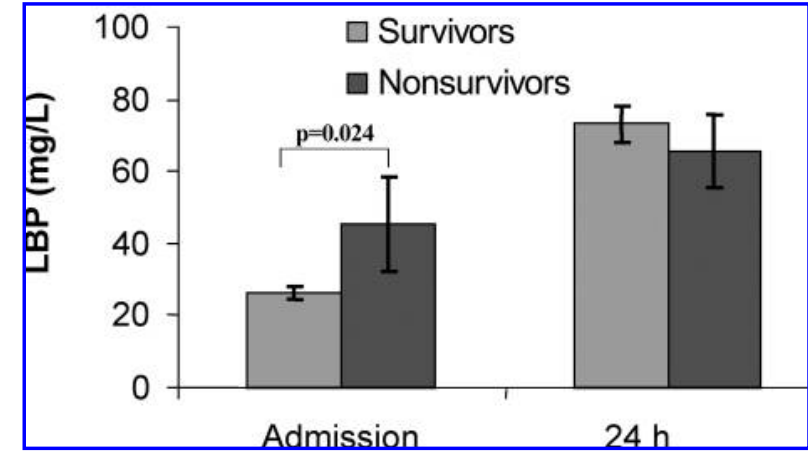

FIG. 5. Concentration of lipopolysaccharide-binding protein (LBP) according to outcome $(n=96)$. Nonsurvivors had significantly higher LBP concentrations on admission.

low concentrations of endotoxin after trauma. Although LBP is synthesized predominantly by the liver, the protein is also produced in multiple extrahepatic locations, including the lung. Fang et al. [25] examined endotoxin concentrations and LBP and CD14 mRNA expression after burns in a rat model. Endotoxin concentrations in the liver, spleen, and lung increased markedly after the injury, with the highest concentration in the liver. The expression of both tissue LBP and CD14 mRNA also rose significantly, peaking at $12 \mathrm{~h}$ post-burn and then decreasing gradually. Expression of the LBP gene had returned to baseline by $48 \mathrm{~h}$. This study also identified a correlation between high LPS and expression of LBP/CD14 mRNA and TNF- $\alpha$ mRNA in tissues. The authors postulated that excessive LBP and CD14 mRNA expression might be associated with enhanced synthesis and release of TNF- $\alpha$ stimulated by endotoxin translocation after major burns.

Upregulation of LBP mRNA expression in liver, lungs, and kidney also was documented in a rat model after hemorrhagic shock and resuscitation without direct tissue injury [30]. The administration of LPS after hemorrhagic shock was associated with significantly higher concentrations of TNF- $\alpha$ than were found in the experimental groups exposed to either shock or LPS alone. These data suggest that upregulation of LBP expression is a major molecular mechanism increasing the sensitivity to endogenous endotoxin after trauma or hemorrhagic shock. In contrast, studies in human trauma have documented reduced responsive- ness of peripheral blood monocytes to LPS and decreased secretion of proinflammatory cytokines, and this endotoxin/LPS tolerance may be associated with changes in the intracellular signals that link monocyte membrane LPS receptors to protein kinase C [31] and to soluble serum factors released systemically after trauma [32].

Other investigators have hypothesized that greater local expression of LBP primes tissues to secondary LPS-mediated damage. Klein et al. [33] documented that local pulmonary LBP and CD14 mRNA were both upregulated after either systemic or local (intratracheal) LPS exposure in a rat model. Intratracheal LPS administration also was associated with a significant increase in TNF- $\alpha$. There is concern that upregulation of LBP may render the lung more susceptible to local immune overactivation and injury during subsequent exposure to LPS.

Similarly, Martin et al. showed that immunoreactive LBP was detectable in bronchoalveolar lavage fluid of patients with acute respiratory distress syndrome [34]. Furthermore, purified LBP enhanced the response of human and rabbit alveolar macrophages to LPS, with earlier onset and greater TNF- $\alpha$ production at an LPS threshold dose that was as much as 1,000-fold lower. These authors concluded that LBP accumulates in the lungs of patients with lung injury and plays an important role in augmenting LPS-stimulated TNF- $\alpha$ gene expression in alveolar macrophages by a pathway that depends on the CD14 receptor.

Table 4. Time-Dependent Changes in Lipopolysaccharide-Binding Protein in Trauma: LOGISTIC Regression ANALysis

\begin{tabular}{llc}
\hline & \multicolumn{2}{c}{ Mortality } \\
\cline { 2 - 3 } Variable & Odds ratio $(95 \% \mathrm{CI})$ & $P$ \\
\hline Admission concentration & $1.02(1.00,1.04)$ & 0.042 \\
24-h concentration & $0.99(0.98,1.01)$ & 0.62 \\
Admission concentration & $2.13(0.52,8.77)$ & 0.297 \\
$\quad \geq 20 \mathrm{mg} / \mathrm{L}$ & & \\
\hline
\end{tabular}

Difference did not achieve statistical significance, likely because of size of sample.

Those who died had significantly higher values on admission, with a 1.02-fold increase in odds of death for every unit increase in LBP. 


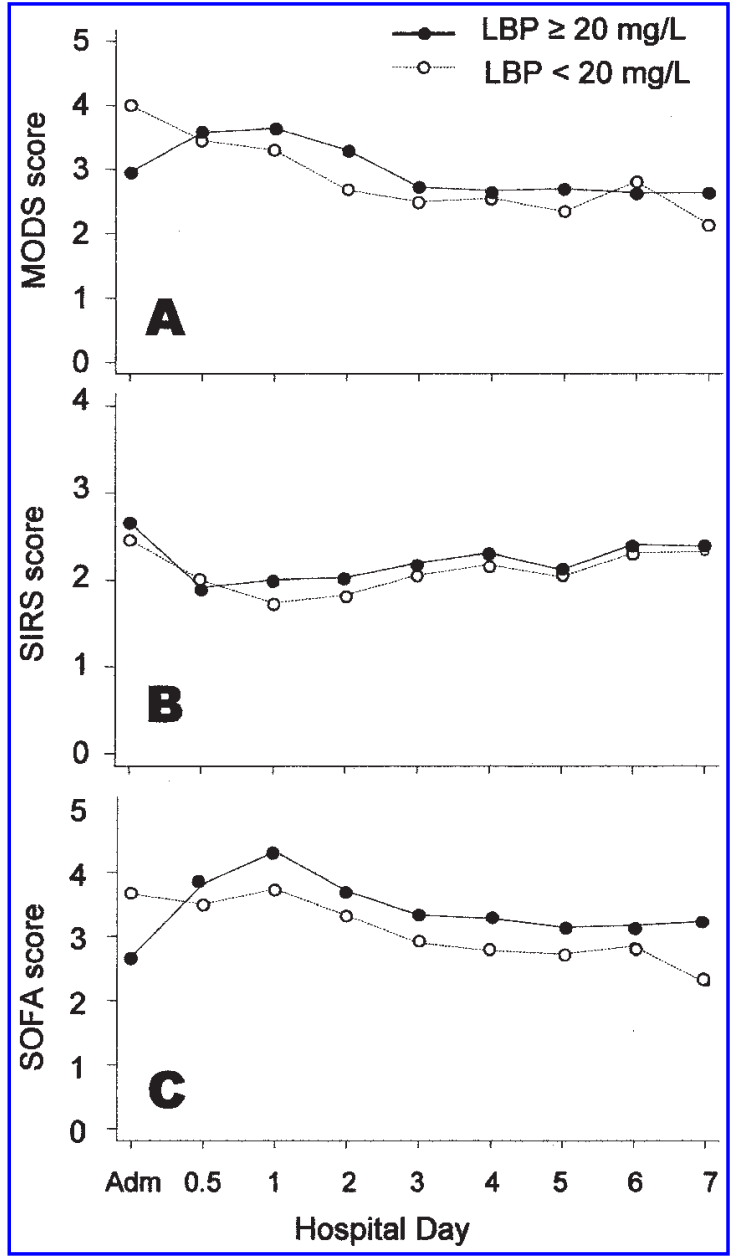

FIG. 6. Admission lipopolysaccharide-binding protein concentration and serial systemic inflammation response score, multiple organ dysfunction score, and sequential organ failure assessment score $(n=96)$.

Lipopolysaccharide-binding protein also is an essential component of an effective innate immune response to infection. Mice deficient in the LBP gene $\left(\mathrm{LBP}^{-/-}\right)$are highly susceptible to E. coli peritonitis, as indicated by earlier death, faster bacterial dissemination to the blood, impaired bacterial clearance from the peritoneal cavity, and more severe remote organ damage than are seen in wild-type mice [35]. Fan et al. observed a significant increase in the mortality rate, earlier onset of bacteremia, and greater pulmonary bacterial loads in $\mathrm{LBP}^{-/-}$mice compared with controls challenged with direct intratracheal inoculation of Klebsiella pneumoniae [36]. Furthermore, total lung myeloperoxidase activity, neutrophil recruitment to the alveolar space, and concentrations of $\mathrm{KC}$ (a chemokine involved in neu- trophil recruitment) in bronchoalveolar lavage fluid and lung homogenates were significantly diminished in $\mathrm{LBP}^{-/-}$mice compared with control animals. Together, these findings suggest that LBP is essential to the pulmonary innate immune response to bacteria.

Early studies in humans documented that LBP serum concentrations range from 1-24 $\mathrm{mcg} / \mathrm{mL}$ and increase significantly in the presence of bacterial infection $[37,38]$. Compared with healthy controls, LPS-challenged volunteers and patients with sepsis exhibit significantly higher plasma concentrations of LBP $(p<0.01)$. Three additional studies have examined plasma concentrations of LBP in patients with severe sepsis and septic shock. Opal et al. performed the largest study to date, with measurements of plasma endotoxin and LBP in 253 patients at the onset of severe sepsis or septic shock [39]. The concentration of LBP was elevated in $97 \%$ of the patients: median, 31.2 $\mathrm{mcg} / \mathrm{mL}$ (range $4.1-162 \mathrm{mcg} / \mathrm{mL}$; interquartile range, $22.5-47.7 \mathrm{mcg} / \mathrm{mL}$ ) compared with a normal value of $4.1 \pm 1.65 \mathrm{mcg} / \mathrm{mL}$. The LBP concentrations were lower in nonsurvivors than survivors ( $28.0 \mathrm{vs} .33 .2 \mathrm{mcg} / \mathrm{mL}$; $<<0.05$ ) over the 28-day study period. This finding was in contrast to those of other studies, in which elevated plasma concentrations of LBP were associated with adverse patient outcomes [40,41].

More recently, Zweigner et al. analyzed serum LBP concentrations in 63 patients with severe sepsis or septic shock [42]. For the entire study cohort, the median LBP concentration at the onset of sepsis was $46.2 \mathrm{mg} / \mathrm{L}$ (range 3.74-155 mg/L), significantly higher than that of healthy volunteers $(7.94 \mathrm{mg} / \mathrm{L}$; range 1.85-17.4 mg/L). Peak LBP concentrations were reached after a median of $40 \mathrm{~h}$ (range 1-120 h) from the onset of severe sepsis. No significant difference in serum LBP concentration was observed in survivors compared with nonsurvivors ( 44.2 vs. $55.5 \mathrm{mg} / \mathrm{L}$ ). Multivariate analysis including severity of infection as a covariate revealed that LBP was not a significant independent predictor of death. Blairon et al. [43] also examined LBP serum concentrations in 24 patients with severe sepsis. The concentration was significantly higher in the septic patients $(46.4 \pm 28.3 \mathrm{mcg} / \mathrm{mL})$ than in healthy volunteers (5.7 $\pm 1.9 \mathrm{mcg} / \mathrm{mL} ; \mathrm{p}<0.0001)$, but 
no difference was noted between survivors and nonsurvivors.

To our knowledge, no prior study has investigated time-dependent alterations in LBP concentrations in human trauma victims. The mean LBP concentrations on admission and at $24 \mathrm{~h}$ after admission were similar to the concentrations previously reported in septic patients. It should be recognized, however, that none of these trauma patients had infection at the time of hospital admission. This findingthat plasma LBP concentrations are increased to the same degree as in patients with severe sepsis and septic shock-is interesting, but the underlying mechanism is not known. We can postulate that gut-derived endotoxin may stimulate the LBP increase, because high plasma endotoxin concentrations have been identified in human trauma victims. For example, in a series of 20 patients with multiple injuries, plasma endotoxin concentrations were at their peak at admission, decreasing thereafter to almost normal values within five days [44].

Importantly, we found that admission LBP concentrations in trauma patients were significantly greater in nonsurvivors than in survivors. Studies in septic patients have yielded conflicting data in this regard, with one study documenting lower LBP concentrations and two studies higher LBP concentrations associated with death. We also identified a correlation between age and admission LBP concentrations. That is, older trauma patients (age $\geq 65$ years) had higher admission LBP concentrations than younger patients. This correlation of LBP with age has not been identified in studies in septic patients.

We attempted to categorize trauma patients as low or high LBP on the basis of their admission LBP concentration in an effort to define a concentration that could identify a patient as being at high risk for an adverse outcome. We found that the mortality rate was doubled $(13.5 \%$ vs. $6.8 \%)$ in patients with admission plasma LBP $>20 \mathrm{mg} / \mathrm{L}$. Additional studies with a larger sample will be required to validate this assay as a rational approach to determining prognosis.

Laboratory biomarkers for outcome in trauma are not available currently but would be helpful to identify patients at high risk of death. The ad- mission LBP concentration is promising, despite the fact that the independent prognostic value of LBP was not incremental to clinical outcome predictors (including age and ISS) in logistic regression analysis. We currently use abnormal cardiac troponin concentrations to diagnose acute myocardial damage, but in acute coronary syndromes, elevation of cardiac troponin at admission does not increase the prognostic capacity of a clinical risk model that includes baseline clinical variables and quantitative electrocardiographic ischemia data [45]. Therefore, quantitative biomarkers would be of great utility in clinical medicine.

It has recently been documented that the response to LPS is highly variable as a result of genetic diversity. Single-nucleotide polymorphisms in the gene encoding Toll-like receptor 4 (the principal receptor for LPS) are associated with systemic inflammatory hyporesponsiveness or hyperresponsiveness to inhaled LPS in healthy volunteers [46]. Low responders have significantly lower white blood cell counts and lower blood concentrations of C-reactive protein and LBP than high responders. No studies to date have examined similar genetic polymorphisms for LPS responsiveness in trauma victims, but such differences likely exist. Future studies should aim to correlate such polymorphisms with plasma LBP concentrations in trauma patients.

There are substantial limitations to this study. First, this is a single-institution study with a small sample. Second, the majority of the study population sustained moderate to severe injury (mean ISS, 23); we did not have a control group that sustained less severe injury. Therefore, the statistical analyses that evaluated the correlation between plasma LBP concentration and injury severity may not have had an adequate range of ISS values to assess this association fully. Additional studies will need to enroll patients with lower injury severity. Third, the majority of the study cohort had evidence of SIRS and organ dysfunction, with only a small number $(n=22)$ having a MODS of 0 on admission. Future studies will need to examine trauma patients without SIRS or organ dysfunction on admission in order to characterize fully the plasma LBP response to acute injury. Fourth, we examined plasma LBP concentrations at 
only two time points. The kinetics of LBP expression in response to trauma in humans have not been established. Neither the rate of change of LBP over time nor the maximum value of LBP production after injury is known. Further studies will be required to determine the peak and nadir LBP concentrations after trauma. Furthermore, whether it is the rate of change in LBP concentration or the peak concentration of LBP that has pathophysiologic or prognostic significance is not yet known. In this initial study, we have demonstrated that plasma concentrations of LBP in trauma victims soon after injury have prognostic significance, and further studies are warranted. Lipopolysaccharide-binding protein should be examined critically as an early biomarker of adverse outcome after traumatic injury.

\section{REFERENCES}

1. Available at http://www.cdc.gov/nchs/fastats/injury.htm

2. Bochicchio GV, Napolitano LM, Joshi M, et al. Systemic inflammatory response syndrome score at admission independently predicts infection in blunt trauma patients. J Trauma 2001;50:817-820.

3. Vincent JL. Nosocomial infections in adult intensive care units. Lancet 2003;361:2068-2077.

4. Marshall JC. SIRS and MODS: What is their relevance to the science and practice of intensive care? Shock 2000;14:586-589.

5. Marshall JC, Vincent JL, Fink MP, et al. Measures, markers and mediators: Toward a staging system for clinical sepsis. A report of the Fifth Toronto Sepsis Roundtable, Toronto, Ontario, Canada, October 25-26, 2000. Crit Care Med 2003;31:1560-1567.

6. Tobias PS, Soldau K, Ulevitch RJ. Isolation of a lipopolysaccharide-binding acute phase reactant from rabbit serum. J Exp Med 1986;164:777-793.

7. Hailman E, Lichenstein HS, Wurfel MM, et al. Lipopolysaccharide (LPS)-binding protein accelerates the binding of LPS to CD14. I Exp Med 1994;179: 269-277.

8. Schumann RR, Leong SR, Flaggs GW, et al. Structure and function of lipopolysaccharide binding protein. Science 1990;249:1429-1431.

9. Mathison JC, Tobias PS, Wolfson E, Ulevitch RJ. Plasma lipopolysaccharide (LPS)-binding protein: A key component in macrophage recognition of gramnegative LPS. J Immunol 1992;149:200-206.

10. Lamping N, Dettmer R, Schroder NW, et al. LPS-binding protein protects mice from septic shock caused by LPS or gram-negative bacteria. I Clin Invest 1998;101: 2065-2071.
11. Tobias PS, Soldau K, Gegner JA, et al. Lipopolysaccharide binding protein-mediated complexation of lipopolysaccharide with soluble CD14. J Biol Chem 1995;270:10482-10488.

12. Ulevitch RJ, Johnston AR, Weinstein DB. New function for high density lipoproteins: Their participation in intravascular reactions of bacterial lipopolysaccharides. J Clin Invest 1979;64:1516-1524.

13. Ulevitch RJ, Johnston AR. The modification of biophysical and endotoxic properties of bacterial lipopolysaccharides by serum. I Clin Invest 1978;62: 1313-1324.

14. Wurfel MM, Kunitake ST, Lichenstein $\mathrm{H}$, et al. Lipopolysaccharide (LPS)-binding protein is carried on lipoproteins and acts as a cofactor in the neutralization of LPS. J Exp Med 1994;180:1025-1035.

15. Zweigner J, Gramm HJ, Singer OC, et al. High concentrations of lipopolysaccharide-binding protein in serum of patients with severe sepsis or septic shock inhibit the lipopolysaccharide response in human monocytes. Blood 2001;98:3800-3808.

16. Myc A, Buck J, Gonin J, et al. The level of lipopolysaccharide-binding protein is significantly increased in plasma in patients with the systemic inflammatory response syndrome. Clin Diagn Lab Immunol 1997;4: 113-116.

17. Erwin PJ, Lewis H, Dolan S, et al. Lipopolysaccharide binding protein in acute pancreatitis. Crit Care Med 2000;28:104-109.

18. Sablotzki A, Borgermann J, Baulig W, et al. Lipopolysaccharide-binding protein (LBP) and markers of acute-phase response in patients with multiple organ dysfunction syndrome (MODS) following open heart surgery. Thorac Cardiovasc Surg 2001;49:273-278.

19. Jack RS, Fan X, Bernheiden M, et al. Lipopolysaccharide-binding protein is required to combat a murine gram-negative bacterial infection. Nature 1997;389: 742-745.

20. Froon AH, Dentener MA, Greve JW, et al. Lipopolysaccharide toxicity-regulating proteins in bacteremia. J Infect Dis 1995;171:1250-1257.

21. Fan X, Stelter F, Menzel R, et al. Structures in Bacillus subtilis are recognized by CD14 in a lipopolysaccharide binding protein-dependent reaction. Infect Immun 1999;67:2964-2968.

22. Savedra R Jr, Delude RL, Ingalls RR, et al. Mycobacterial lipoarabinomannan recognition requires a receptor that shares components of the endotoxin signaling system. J Immunol 1996;157:2549-2554.

23. Oude Nijhuis CS, Vellenga E, Daenen SM, et al. Lipopolysaccharide-binding protein: A possible diagnostic marker for gram-negative bacteremia in neutropenic cancer patients. Intensive Care Med 2003; 29:2157-2161.

24. Prucha M, Herold I, Zazula R, et al. Significance of lipopolysaccharide-binding protein (an acute phase protein) in monitoring critically ill patients. Crit Care 2003;7:R154-159.

25. Fang CW, Yao YM, Shi ZG, et al. Lipopolysaccharidebinding protein and lipopolysaccharide receptor 
CD14 gene expression after thermal injury and its potential mechanism(s). I Trauma 2002;53:957-967.

26. Fang WH, Yao YM, Shi ZG et al. Effect of recombinant bactericidal/permeability-increasing protein on endotoxin translocation and lipopolysaccharide-binding protein/CD14 expression in rats after thermal injury. Crit Care Med 2001;29:1452-1459.

27. Napolitano LM, Ferrer T, McCarter RJ Jr, Scalea TM. Systemic inflammatory response syndrome score at admission independently predicts mortality and length of stay in trauma patients. I Trauma 2000;49:647-652.

28. Bota DP, Melot C, Ferreira FL, et al. The multiple organ dysfunction score (MODS) versus the sequential organ failure assessment (SOFA) score in outcome prediction. Intensive Care Med 2002;28:1619-1624.

29. Baker SP, O’Neill B, Haddon W Jr, Long WB. The injury severity score: A method for describing patients with multiple injuries and evaluating emergency care. Jrauma 1974;14:187-196.

30. Jiang JX, Diao YF, Tian KL, et al. Effect of hemorrhagic shock on endotoxin-inducing TNF production and intra-tissue lipopolysaccharide-binding protein mRNA expression and their relationship. Shock 1997;7: 206-210.

31. Keel M, Schregenberger N, Steckholzer U, et al. Endotoxin tolerance after severe injury and its regulatory mechanisms. J Trauma 1996;41:430-438.

32. Majetschak M, Borgermann J, Waydhas C, et al. Whole blood tumor necrosis factor-alpha production and its relation to systemic concentrations of IL-4, IL10 and transforming growth factor-beta 1 in multiply injured blunt trauma victims. Crit Care Med 2000; 28:1847-1853.

33. Klein RD, Su GL, Aminlari A, et al. Pulmonary LPSbinding protein (LBP) upregulation following LPSmediated injury. I Surg Res 1998;78:42-47.

34. Martin TR, Mathison JC, Tobias PS, et al. Lipopolysaccharide binding protein enhances the responsiveness of alveolar macrophages to bacterial lipopolysaccharide: Implications for cytokine production in normal and injured lungs. J Clin Invest 1992;90:2209-2219.

35. Knapp S, de Vos AF, Florquin S, et al. Lipopolysaccharide binding protein is an essential component of the innate immune response to Escherichia coli peritonitis in mice. Infect Immun 2003;71:6747-6753.

36. Fan MH, Klein RD, Steinstraesser L, et al. An essential role for lipopolysaccharide-binding protein in pulmonary innate immune responses. Shock 2002; 18:248-254.

37. Opal SM, Palardy JE, Marra MN, et al. Relative concentrations of endotoxin-binding proteins in body fluids during infection. Lancet 1994;344:429-431.

38. Calvano SE, Thompson WA, Marra MN, et al. Changes in polymorphonuclear leukocyte surface and plasma bactericidal/permeability increasing pro- tein and plasma lipopolysaccharide-binding protein during endotoxemia or sepsis. Arch Surg 1994;129: 220-226.

39. Opal SM, Scannon PJ, Vincent JL, et al. Relationship between plasma levels of lipopolysaccharide (LPS) and LPS-binding protein in patients with severe sepsis and septic shock. J Infect Dis 1999;180:1584-1589.

40. Carroll SF, Dedrick L, White ML. Plasma levels of lipopolysaccharide binding protein (LBP) correlate with outcome in sepsis and other patients [abstract 101]. In: Abstracts of the Sixth Vienna Shock Forum. Vienna, Austria. 1997:8-11.

41. Schumann RR, Zweigner J, Lamping N, Gramm HJ. Significantly elevated levels of lipopolysaccharide binding protein (LBP) in patients with severe sepsis: A prospective cohort study with 109 surgical ICU patients. [abstract LB17]. In: Program and Abstracts of the 36th Interscience Conference on Antimicrobial Agents and Chemotherapy. New Orleans. 1996.

42. Zweigner J, Gramm HJ, Gsinger OC, et al. High concentrations of lipopolysaccharide-binding protein in serum of patients with severe sepsis or septic shock inhibit the lipopolysaccharide response in human monocytes. Blood 2001;98:3800-3808.

43. Blairon L, Wittebole X, Laterre PF. Lipopolysaccharide-binding protein serum levels in patients with severe sepsis due to gram-positive and fungal infections. J Infect Dis 2003;187:287-291.

44. Buttenschoen K, Berger D, Strecker W, et al. Association of endotoxemia and production of antibodies against endotoxins after multiple injuries. I Trauma 2000;48:918-923.

45. Oltrona L, Ottani F, Galvani M; Italian Working Group on Atherosclerosis, Thrombosis, and Vascular Biology and the Associazione Nazionale Medici Cardiologi Ospedalieri (ANMCO). Clinical significance of a single measurement of troponin-I and C-reactive protein at admission in 1773 consecutive patients with acute coronary syndromes. Am Heart J 2004;148: 405-415.

46. Michel O, LeVan TD, Stern D, et al. Systemic responsiveness to lipopolysaccharide and polymorphisms in the Toll-like receptor 4 gene in human beings. I Allergy Clin Immunol 2003;112:923-929.

Address reprint requests to: Dr. Lena M. Napolitano Department of Surgery

University of Michigan School of Medicine Room 1C421 University Hospital 1500 East Medical Center Drive Ann Arbor, MI 48109-0033

E-mail: lenan@umich.edu 

This article has been cited by:

1. Yasser Sakr, Ulricke Burgett, Flavio E. Nacul, Konrad Reinhart, Frank Brunkhorst. 2008. Lipopolysaccharide binding protein in a surgical intensive care unit: A marker of sepsis?*. Critical Care Medicine 36:7, 2014-2022. [CrossRef]

2. Jorge I. F. Salluh, Patrícia T. Bozza. 2008. Biomarkers of sepsis: Lost in translation?*. Critical Care Medicine 36:7, 2192-2194. [CrossRef] 